\title{
A controlled study of palpatory diagnostic procedures: Assessment of sensitivity and specificity
}

\author{
ROBERT S. TARR, PH.D. \\ RICHARD A. FEELY, D.O \\ DANIEL L. RICHARDSON, PH.D. \\ Chicago, Illinois \\ ANTHONY L. MULLOY, PH.D., D.O \\ Waterbury, Connecticut \\ KENNETH E. NELSON, D.O \\ WARD E. PERRIN, D.O. \\ EDGAR F. ALLIN, M.D \\ MARK E. EFRUSY, D.O. \\ STEPHEN I. GREENSTEIN, D.O \\ RICHARD D. VATT, M.ED \\ Chicago, Illinois
}

A study was conducted to determine if experienced osteopathic physicians could diagnose disease states using palpatory findings as their source of diagnostic clues. Five examiners saw a total of 100 subjects. Two of the examiners were allowed to palpate the subject; the other 3 examiners were not. None of the 5 examiners had any knowledge of the subject's medical history, and none were allowed to talk to the subjects. Thus the nonpalpating examiners only had visual clues to aid in diagnosis, while the palpating examiners had both visual clues and palpatory clues. A comparison of the diagnostic accuracy of the palpating and nonpalpating examiners thus indicated the ability of the palpating physicians to distinguish disease states by palpatory findings alone. One hundred subjects

Two major concepts of osteopathic theory are facilitation of spinal cord transmission and viscerosomatic reflex relationships. A great deal of evidence derived from basic science research ${ }^{1-4}$ has documented and validated these concepts as reasonable theoretical bases for palpatory techniques. were examined: 22 patients with documented gastrointestinal disease, 31 patients with documented asthma (but were in remission), and 47 control subjects with a negative history for either gastrointestinal pathology or asthma. Controls were matched for appearance, age, sex, race, and weight, with the 2 groups of patients. The results showed that neither the palpating physicians nor the nonpalpating could correctly categorize the subjects as gastrointestinal patients, asthma patients, or controls. The palpating physicians did not demonstrate any increased diagnostic accuracy over the nonpalpating examiners. Reasons for these negative results are discussed, as is the issue of using appropriate control procedures in osteopathic clinical research.

For example, $\mathrm{Eble}^{4}$ demonstrated quantifiable functional viscerosomatic relationships in awake animals; these viscerosomatic reflexes were reproducible and followed a segmental pattern. Other experiments, ${ }^{1,3,5,6}$ which ranged from electrical recording of nerve trunk activity to thermographic 
correlates of palpatory findings, firmly established the physiologic groundwork for postulating a reflex arc communication of the visceral state to the somatic musculature.

Clinical osteopathic research efforts have been undertaken to demonstrate the role of viscerosomatic reflexes in osteopathic medical practice. Kappler ${ }^{7}$ reported detectable structural patterns for specific diagnosis of visceral and inflammatory disease states. In this study, osteopathic physicians examined patients without knowledge of their health status. They performed extensive palpatory examinations, including evaluations of skin, muscle tension, and range of motion. The results were correlated with the patient's condition, and deviations from a composite pattern of tissue reaction were noted. It was concluded that a specific illness is characterized by a unique set of palpatory findings. For example, while tissue reaction at the level of the second cervical vertebra on the left had an overall incidence of approximately 15 percent, 75 percent of the patients with esophagitis had this reaction. These results were explained in terms of the autonomic innervation of the visceral structures that would underlie viscerosomatic reflex arcs.

In a series of studies involving more than 6,000 patients, Kelso, Larson, and Kappler ${ }^{3}$ correlated palpatory findings with various disease states. An increased or decreased frequency of findings in somatic tissues segmentally related to diseased viscera was noted. Unique patterns of palpatory findings were noted for bronchitis, acute appendicitis, gastric ulcer, cholecystitis, and cervicitis. These results were interpreted in terms of viscerosomatic reflex relationships. Johnston and associates ${ }^{8}$ reported on a significantly higher incidence of a pattern of palpatory findings in hypertensives than in normotensives. Cox and coworkers ${ }^{9}$ correlated palpatory findings with coronary artery disease in 97 patients. Changes at T4 were positively correlated with coronary vessel stenosis of 50 percent or more in at least one artery. Rosero and coresearchers ${ }^{10}$ reported a retrospective correlation of palpatory findings and acute myocardial infarction. The results showed statistically significant correlations between specific palpatory findings and location of the infarction within the myocardium (anterior septum, posterior wall, et cetera).

In general, there is extensive literature associating specific palpatory findings to disease states, especially cardiovascular, gastrointestinal, and respiratory disorders. In none of these studies did the examiner attempt to diagnose on the basis of the palpatory findings. A subconscious bias in the correlational analysis can occur; therefore, the di- agnostic utility of correlations derived from such studies must be tested by investigations of a prospective nature. For example, if a certain palpatory finding is found to be associated with a specific disease and is not found in normal individuals, the examiner should be able to determine the presence of this disease from the palpatory record alone. A recent study by Beal ${ }^{11}$ presents a comprehensive descriptive account of the palpatory findings in a variety of cardiovascular diseases. The study included a physician-blind, prospective part, which was designed to test the predictive value of the palpatory pattern that was found in known cardiovascular patients. The palpatory findings were accurate in indicating the presence of cardiac or gastrointestinal disease in 76 percent of examinations.

Because just this one study has been conducted utilizing a prospective physician-blind approach to palpatory diagnosis, we designed a controlled study to assess the accuracy of palpatory clues in making a medical diagnosis. An issue that especially needed to be addressed was that of controls. In our study, we attempted to rule out inadvertent error by utilizing control procedures essential to eliminating bias. We were careful to control for nonpalpatory medical clues. An extreme illustration of the need to do this involves a hypothetical situation in which a physician claims that amputation of an upper limb results in a unique set of palpatory findings in the thoracic paraspinal musculature. If, further, this physician attempted to prove this hypothesis by a prospective study in which he/she were to go into the patient's room (with no prior knowledge of the medical record), palpate the patient, and declare whether the subject were an amputee, clearly the visual evidence alone would invalidate the conclusion. In an actual prospective study on palpatory accuracy, one must control for a variety of subtle nonpalpatory clues, including visual appearance of the patient, sounds, reactions, medications in the room, the wing of the hospital where the patient is located, and so forth. Without eliminating these factors, any success above chance level cannot be attributed to palpatory findings alone, because even the most honest, objective examiner can be swayed by subliminal observation of nonpalpatory clues.

The present study was designed to assess the accuracy of diagnostic osteopathic palpatory technique. The specific aim was to determine whether a physician could, on the basis of palpatory findings alone, distinguish among three groups of patients - those with active gastrointestinal disorders, those with asthma in remission, and normal controls. 


\section{Procedure}

Three groups of research subjects were evaluated by five examiners. The three groups of subjects consisted of the following: (1) 22 patients (13 female, 9 male) with a documented gastrointestinal disorder (endoscopic evidence of inflammation, ulcer, or neoplasm of the esophagus, stomach, small intestine, or large intestine). All of these patients had a negative history for asthma. (2) 31 patients (15 female, 16 male) with a documented history of asthma (at least 15 percent improvement of forced expiratory volume at 1 second following bronchodilator treatment) who were in remission. All of these patients had a negative history of gastrointestinal disease or recent gastrointestinal upset. (3) 47 subjects ( 27 female, 20 male) with a negative history for both gastrointestinal disorders and asthma. An attempt was made to match the age, weight, sex, and race of these control subjects to the 53 patients.

The five examiners included two osteopathic physicians who were free to both visually inspect and to palpate the subjects, an osteopathic physician who could only visually inspect the subjects, an allopathic physician who could only visually inspect the subjects, and a basic scientist with no clinical experience who could only visually inspect the subjects. None of the examiners had any experience with the subjects or any prior knowledge of their medical condition. None of the examiners spoke to the subjects except to instruct him/her to move. The subjects did not answer any questions or talk with the examiners. At the end of the examination, each examiner assigned the subject to one of three categories-gastrointestinal, asthma, or control. The examiners also wrote a note describing the reasons (if any) that caused them to assign a subject to a given category.

All subjects were examined in a neutral clinic room; that is, an examining room that was not connected with either gastroenterology or pulmonary medicine. All subjects were robed in a standard hospital gown. Two to 5 subjects were examined per week, and the project took 11 months to complete. The first 63 subjects, who were examined during the first 7 months of the study, were in full view of the examiners. That is, the examiner could see the subject's face and could ask him/her to move, sit, or lie down. Analysis of the data collected during the first 7 months suggested that being able to see the subject was distracting to the palpators. It was thought that palpatory accuracy might improve if visual clues were diminished. Accordingly, 37 subjects examined during the last 4 months of the study were screened from all of the examiners by a surgical split sheet, which was arranged so

\begin{tabular}{|c|c|c|c|}
\hline Evaluator & $\begin{array}{l}\text { Palpate for } \\
\text { osteopathic } \\
\text { findings }\end{array}$ & $\begin{array}{l}\text { Visually inspect } \\
\text { for medical } \\
\text { clues }\end{array}$ & $\begin{array}{l}\text { Visually inspect } \\
\text { for nonmedical } \\
\text { clues }\end{array}$ \\
\hline D.O. examiner & + & + & + \\
\hline D.O. control & - & + & + \\
\hline M.D. control & - & + & + \\
\hline Basic scientist & - & - & + \\
\hline
\end{tabular}

that an examiner could view only the neck and back of the seated subject. The subject's movement was restricted to simple turning and bending, as requested by the examiner.

Only one examiner was allowed in the room with a subject, and examiners were not permitted to talk with each other before categorizing subjects. Examiners were not informed of the actual category of any subject until all 100 subjects had been processed. Table 1 summarizes the procedures used by each examiner.

For each examiner, diagnostic sensitivity and specificity were computed for each category and for all categories combined. Sensitivity was defined as the number of true positives (those correctly identified as having a condition) divided by the sum of the false negatives and the true positives (that is, divided by the total number of subjects who actually had the condition). Specificity was defined as the true negatives (the number of people without a condition who were diagnosed as not having the condition) divided by the sum of the false positives and the true negatives (that is, divided by the total number of subjects who actually did not have the condition).

\section{Results}

Table 2 displays the tabulated raw data. The data from the first 63 subjects (those who could be seen by the examiners) and from the last 37 subjects (those behind a screen) were combined, because there were no significant differences (chi square analysis) in the percentage correct or percentage incorrect when these groups were analyzed separately. For each examiner, the number of subjects seen and the number of subjects assigned to each diagnostic category are shown. For example, palpator 1 saw 74 of the 100 subjects- 36 controls, 18 documented gastrointestinal patients, and 20 documented asthma patients. Of the 36 control subjects, palpator 1 assigned 20 to the control category ( 20 true positives) and 6 and 10 to the gastrointestinal and asthma categories, respectively (16 false negatives).

Further, palpator 1 identified 8 gastrointestinal 


\begin{tabular}{|c|c|c|c|c|c|c|c|c|c|c|c|c|c|}
\hline \multirow[b]{2}{*}{ Evaluator } & \multicolumn{4}{|c|}{ Controls } & \multicolumn{4}{|c|}{ Gastrointestinal } & \multicolumn{4}{|c|}{ Asthma } & \multirow[b]{2}{*}{ Total } \\
\hline & $\mathrm{C}$ & GI & $\mathrm{A}$ & No. & $\mathrm{C}$ & GI & A & No. & $\mathrm{C}$ & GI & A & No. & \\
\hline Palpator 1 & 20 & 6 & 10 & 36 & 8 & 5 & 5 & 18 & 13 & 2 & 5 & 20 & 74 \\
\hline Palpator 2 & 11 & 20 & 8 & 39 & 2 & 10 & 5 & 17 & 7 & 5 & 8 & 20 & 76 \\
\hline $\begin{array}{l}\text { Physician } \\
\quad \text { nonpalpator } 1 \\
\text { Physician }\end{array}$ & 17 & 7 & 2 & 26 & 8 & 3 & 1 & 12 & 8 & 2 & 4 & 14 & 52 \\
\hline $\begin{array}{l}\text { Physician } \\
\text { nonpalpator } 2 \\
\text { Basic }\end{array}$ & 22 & 10 & 2 & 34 & 6 & 4 & 3 & 13 & 13 & 2 & 7 & 22 & 69 \\
\hline scientist & 19 & 9 & 10 & 38 & 4 & 5 & 9 & 18 & 8 & 4 & 12 & 24 & 80 \\
\hline $\begin{array}{l}\mathrm{C}=\text { examiner assig } \\
\mathrm{GI}=\text { examiner assi } \\
\mathrm{A}=\text { examiner assig } \\
\text { No. = total number } \\
\text { Total = total numbe }\end{array}$ & $\begin{array}{l}f \text { a su } \\
\text { of a s } \\
f \text { a su } \\
\text { cts in } \\
\text { iects }\end{array}$ & $\begin{array}{l}\text { ect to } \\
\text { ject to } \\
\text { ect to } \\
\text { ne cat }\end{array}$ & $\begin{array}{l}\text { e cor } \\
\text { he ge }\end{array}$ & $\begin{array}{l}\text { rol cate } \\
\text { trointes } \\
\text { ma cate } \\
\text { n by a }\end{array}$ & ry. & & & & & & & & \\
\hline
\end{tabular}

patients and 13 asthma patients as controls. Therefore, with respect to controls, palpator 1 had 21 false positives. Lastly, note that palpator 1 indicated 10 gastrointestinal patients and 7 asthma patients as noncontrols (that is, having either gastrointestinal disease or asthma). Therefore, with respect to controls, palpator 1 had 17 true negatives.

Table 3 displays the computed sensitivity of the diagnosis (categorization); that is, Table 3 shows the percentage of subjects correctly categorized. For example, palpator 1 correctly categorized 20 of 36 control subjects as such, for a sensitivity of 56 percent. The total percent reflects the correct sensitivity of all 3 groups combined.

Table 4 presents the specificity that each examiner shows for each category. For example, palpator 1 identified 10 of 18 gastrointestinal patients as noncontrols ( 5 were correctly identified and 5 were incorrectly identified as asthma patients) and 7 of 20 asthma patients as noncontrols, for 17 true negatives. He incorrectly identified 8 of the gastrointestinal patients as controls and 13 of 20 asthma patients as controls, for 21 false positives. His specificity was computed by dividing the number of true negatives (17) by the sum of the false positives (21) and the true negatives (17). Thus, with respect to controls, palpator 1 had a specificity of 45 percent (17/38).

\section{Discussion}

The results show that under the restrictions imposed by this study, the palpating physicians did not have a higher sensitivity or specificity of diagnosis than the nonpalpating examiners. Chi square analysis of the palpators' total percentage of correct responses and total percentage of incorrect responses confirms that these values can be explained by chance alone and are not statistically signifi- cant. The large differences among examiners within one group look significant at first glance. For example, palpator 2 showed a 59 percent sensitivity in the gastrointestinal group compared to 25 to 31 percent for the other examiners. However, palpator 2 showed a correspondingly low specificity (58 percent) in the gastrointestinal group compared to the other examiners (68 to 86 percent). That is, palpator 2 tended to diagnose patients as gastrointestinal and, therefore, both correctly and incorrectly placed more patients in that category. In fact, Table 2 reveals that palpator 2 categorized twice as many control subjects as having gastrointestinal disease than did the others. It must be realized that if an examiner were to categorize all 100 subjects into one of the 3 groups, sensitivity within that group would be 100 percent. A second way of appreciating that the differences between examiners within a group were not meaningful is to notice that when sensitivity and/or specificity in all 3 groups of subjects is averaged, the 5 examiners had very similar performances. Any increase in one category was balanced by a decrease in another category.

What is the explanation for these negative results? This complicated question requires an examination of our design in relation to previous studies on palpatory findings, as well as in relation to actual clinical practice. The majority of the studies performed to date correlated palpatory findings with pathologic states. ${ }^{3,7,11,12}$ In some of these,,$^{3,11,12}$ the palpators had no knowledge of the medical condition of the patients palpated. The implication of results that show a correlation between a palpatory finding and a disease state is that the finding could be used to identify the disease. That is, that palpation could be used for diagnosis. Some authors ${ }^{11}$ have maintained this to be true, while others ${ }^{3,7}$ 
Sensitivity (TP divided by FN + TP)

Percent of gastroin- Percent of asthma pa-

Percent of control sub- testinal patients cor- tients correctly identified jects correctly identified rectly identified (GI-GI (A-A divided by the sum (C-C divided by the sum divided by the sum of GI- of A-C, A-GI, and of C-GI, C-A, and C-C)

$\begin{array}{ll}\text { divided by the sum of GI- } & \text { of } \\ \text { C, GI-A, and GI-GI) } & \text { A-A) }\end{array}$

Evaluator

$56 \%(20 / 36)$

$28 \%(11 / 39)$

$28 \%(5 / 18)$

$59 \%(10 / 17)$

A-A)

Palpator 1
Palpator 2

$65 \%(17 / 26)$

$25 \%(3 / 12)$

$25 \%(5 / 20)$

$40 \%(8 / 20)$

$29 \%(4 / 14)$

nonpalpator 1

$65 \%(22 / 34)$

$31 \%(4 / 13)$

$50 \%(19 / 38)$

$28 \%(5 / 18)$

$32 \%(7 / 22)$

$50 \%(12 / 24)$

Total percent

correct

observations

$41 \%(30 / 74)$

$38 \%(29 / 76)$

$46 \%(24 / 52)$

nonpalpator 2
Basic scientist

$\overline{\mathrm{TP}}=$ true positives; $\mathrm{FN}=$ false negatives.

$\mathrm{C}-\mathrm{C}=$ controls correctly identified.

C-GI $=$ controls incorrectly identified as gastrointestinal patients.

C-A = controls incorrectly identified as asthma patients.

GI-GI = gastrointestinal patients correctly identified.

GI-C = gastrointestinal patients incorrectly identified as controls.

GI-A $=$ gastrointestinal patients incorrectly identified as asthma patients.

A-A = asthma patients correctly identified.

A-C $=$ asthma patients incorrectly identified as controls.

A-GI = asthma patients incorrectly identified as gastrointestinal patients.

TABLE 4. SPECIFICITY ACCURACY RATES.

Specificity (TN divided by FP + TN)

Percent of non-controls
correctly identified (GI-
GI plus GI-A plus A-A
plus A-GI divided by the
total number of gastroin-
testinal and asthma pa-
tients seen)

Percent of gastroin- Percent of non-asthmatics testinal patients cor- who were correctly identirectly identified (C-C fied (C-C plus C-GI plus GIplus C-A plus A-A plus A- GI plus GI-C divided by the $\mathrm{C}$ divided by the total

total number of control and number of control and asthma patients seen) tients seen)

gastrointestinal patients seen)

$\begin{array}{ll}86 \%(48 / 56) & 72 \%(39 / 54) \\ 58 \%(34 / 59) & 77 \%(43 / 56)\end{array}$

$78 \%(31 / 40)$

$92 \%(35 / 38)$

$79 \%(44 / 56)$

$68 \%(42 / 62)$

$46 \%(16 / 35)$

$71 \%(30 / 42)$
$89 \%(42 / 47)$

$66 \%(37 / 56)$
Total percent

correct

observations

$70 \%(104 / 148)$

$69 \%(105 / 152)$

$73 \%(76 / 104)$

$74 \%$ (102/138)

$68 \%(109 / 160)$

$\overline{\mathrm{TN}}=$ true negatives; $\mathrm{FP}=$ false positives.

GI-GI = gastrointestinal patients correctly identified.

GI-A = gastrointestinal patients incorrectly identified as asthma patients.

$\mathrm{A}-\mathrm{A}=$ asthma patients correctly identified.

$\mathrm{A}-\mathrm{GI}=$ asthma patients incorrectly identified as gastrointestinal patients.

C-C $=$ controls correctly identified.

C-A $=$ controls incorrectly identified as asthma patients.

A-C $=$ asthma patients incorrectly identified as controls.

C-GI $=$ controls incorrectly identified as gastrointestinal patients.

GI-C = gastrointestinal patients incorrectly identified as controls.

have cautioned that palpatory findings alone cannot be used to form a diagnosis.

Our study was designed to evaluate the accuracy of palpatory findings as the sole source of diagnostic data. Just one study ${ }^{11}$ reported in the literature was designed to see whether a disease state could be identified by palpatory clues alone. Twenty-five patients were examined without prior knowledge of their medical condition. On the basis of palpatory findings alone, each person was assigned to either the category of cardiovascular disease or gastrointestinal disease. Thirteen of the 25 subjects had documented gastrointestinal disease, and 12 had documented cardiovascular disease. The investigator correctly categorized 10 of the gastrointestinal subjects (77 percent sensitivity) and 9 of the cardiovascular subjects ( 75 percent sensitivity). The total percent correct was $76(19 / 25)$. With only 2 groups used, specificity was likewise 76 percent. Although this is clearly a significant value (chance alone would provide 50 percent sensitivity), there were no controls for nonpalpatory clues. Were there subliminal clues that allowed a sensitivity above 50 percent? Because there were no nonpalpator con- 
trol examiners, the degree of nonpalpatory cluing cannot be assessed. In our study, palpator 1 had a total percent correct (sensitivity) of 41 . By chance alone one would expect 33 percent sensitivity, so it appears that this is a significant number. Only by observing that the nonpalpators (who used only visual and auditory clues) did as well as palpator 1 can it be appreciated that the palpatory clues did not provide additional sensitivity in this case. It is our recommendation that any researchers using correlations between palpatory findings and disease states to determine whether these palpatory findings can be used as the sole basis for diagnosis should include nonpalpator control examiners.

It must be emphasized that the design of our experiment forced the examiners to perform under very limited and artificial conditions. Neither of our palpating physicians routinely attempt to diagnose on the basis of palpatory clues alone. Normally, they follow a multistep process. First, they elicit musculoskeletal findings or groups of findings. Then, forming a tentative hypothesis, they begin to distinguish (on the basis of history, physical findings, and further testing) the significant findings from the incidental, the normal from the pathologic, and the visceral from the somatic. Thus, the restricted situation in this study did not assess the accuracy of palpation in a realistic clinical setting.

We conclude only that for asthma in remission and gastrointestinal disease, the experienced osteopathic physicians in this study could not utilize palpatory findings as the sole basis for making an accurate diagnosis. Additional studies using large numbers of examiners should be conducted to determine whether, as a group, osteopathic physicians can rely on palpatory clues alone. Further, asthma in remission and widespread gastrointestinal pathology may not be the best groups to use. Perhaps other sets of pathologies would be found to have a more definite palpatory correlation. The fact that the control examiners were able to do better than chance suggests that visual clues (patient appearance, pattern of breathing) did exist that, in this restricted setting, allowed for some recognition of disease. It should be noted, however, that apparently medical training per se had no value in making an accurate categorization. This indicates that our test situation was sufficiently rigorous to eliminate practically all specific clinical information. A review of the written examiner comments suggests that general patient appearance (for example, thin or obese, breathing difficulty, healthy looking) was the major factor in making the category selection.

\section{Conclusions}

We believe that the widespread reports of specific palpatory findings being associated with pathologic states require that further studies on the accuracy of palpatory findings be conducted. The design of such studies should include an analysis of both total correct and total incorrect observations. Additionally, a well-designed investigation of the accuracy of palpatory diagnostic techniques requires some control for nonpalpatory clues. Finally, it is important that some studies of palpatory accuracy utilizing a realistic clinical setting be conducted.

1. Korr, I.M.: The neural basis of the osteopathic lesion. JAOA 47:191-8, Dec 47

2. Hix, E.L.: Viscero-visceral and somato-visceral reflex communication. In The physiological basis of osteopathic medicine, edited by I.N Kugelmass and G.W. Northup. Postgraduate Institute of Osteopathic Medicine and Surgery, New York, 1967

3. Kelso, A.F., Larson, N.J., and Kappler, R.E.: A clinical investigation of the osteopathic examination. JAOA 79:460-7, Mar 80

4. Eble, J.N.: Patterns of response of the paravertebral musculature to visceral stimuli. Am J Physiol 198:429-33, Feb 60

5. Hix, E.L.: Segmental and suprasegmental reflex influences on kidney function. JAOA 66:999-1000, May 67

6. Hix, E.L.: Uretero-renal reflex facilitating renal vasoconstrictor responses to emotional stress. Am J Physiol 192:191-7, Jan 58

7. Kappler, R.E.: A comparison of structural examination findings obtained by experienced physician examiners and student examiners on hospital patients. JAOA 79:468-71, Mar 80

8. Johnston, W.E., et al.: Identification of stable somatic findings in hypertensive subjects by trained examiners using palpatory examination. JAOA 81:830-6, Aug 82

9. Cox, J.M., et al.: Palpable musculoskeletal findings in coronary artery disease. Results of a double blind study. JAOA 82:832-6, Jul 83

10. Rosero, H.O., et al.: A correlation of palpatory observations with the anatomical locus of acute myocardial infarction (abstract). JAOA 84:74-5, Sep 84

11. Beal, M.C.: Palpatory testing for somatic dysfunction in patients with cardiovascular disease. JAOA 82:822-31, Jul 83

12. Beal, M.C., and Morlock, J.W.: Somatic dysfunction associated with pulmonary disease. JAOA 84:179-83, Oct 84

This study was supported by AOA grant no. 82-01-062.

Accepted for publication in February 1986. Updating, as necessary, has been done by the authors.

Dr. Tarr is a professor of physiology at the Chicago College of Osteopathic Medicine, Chicago, Illinois. Dr. Feely is an associate professor of family medicine at CCOM, as well as in private practice in Chicago. Dr. Richardson is an associate professor of Pharmacology at CCOM. Dr. Mulloy is a resident in internal medicine at the Yale-affiliated Waterbury Hospital Health Center, Waterbury, Connecticut. Dr. Nelson is an associate professor of family medicine, Dr. Perrin is a professor of internal medicine, Dr. Allin is a professor of anatomy, Dr. Efrusy is a professor of internal medicine, and Dr. Greenstein is an associate professor and chairman of the Department of Pulmonary Medicine, all at CCOM. Mr. Vatt is a fourth-year medical student at CCOM.

Dr. Tarr, Chicago College of Osteopathic Medicine, 5200 South Ellis Avenue, Chicago, Illinois 60615. 
DESCRIPTION: Eoch milliliter of NASALCROM* (cromolvn sodium nosal solution, USP) contains $40 \mathrm{mg}$ nasal solution, USP) contiains $40 \mathrm{mg}$ cromolyn sodium in purited woler with benzalkonium chlonide $0.01 \%$ and EDIA (edeldo disodium) $0.01 \%$. INDICATIONS: NASALCROM is indcoted for the prevention and treatment of the symptoms of allergic ininitis. CONTRAINDICATIONS: NASALCROM is contraindicated in those potients who have shown hypersensitivity to any of the ingredients.

PRECAUTIONS: General: Some pafients may experience transient nasal lients may expenence transient nasal stinging and/or sneezing immedidely Except in rare occurrences, these experiences have not caused discontinuation of theropy

In view of the biliary and renal routes of excretion for cromolyn sodium, consideration should be given to decreas. in the dould be giscontinuing the ing the dosage or discontinuing the with impgiton of the drug in patients withimparedrenalorhepatictunction. Corcinogenesis, Mutogenesis, and Impoirment of Fertility: Long term studies in mice ( 12 months intropentioneal treatment followed by 6 months observation), hamsters (12 months introperitoneal treatment followed by 12 months observation), and rots (18 months subcutaneous trectment) showed no neoplastic effect of cromolyn sodium.

No evidence of chromosomal darnoge No evidence of chromosomal darnoge or cytotoxicity was obtained in various mutogenesis studies.

No evidence of impaired fertility was shown in labordtory animal reproduction studies.

Pregnancy: Pregnancy Category B Reproduction shudies with cromolym sodium odministered parenterolly to sodium odmistared parenterally to pregnont mice, coses upio 338 imes the humanclincal doses produced no evidence of letal maliormations. Adverse telal ef lects (increased resorphions and de creased fetal weight) were noted only at the very high parenteral doses that produced maternal toxicity. There are, however, no adequate and wellcontrolled studies in pregnant women. Becouse animal reproduction studies are not olvos predictive of human re sponse, this drug should be used dusponse, this dring should be used during pregnoncy onty if clacty neoded. Drug Interoction During Pregnancy: cromolyn sodium and isoprotereno were studied following subcutaneous injections in pregnant mice. Cromoly sodium alone in doses of 60 to 540 $\mathrm{mg} / \mathrm{kg}$ ( 38 to 338 fimes the human dose) did not couse significant increases in resorptions or major malformations. Isoproterenol alone ot a dose f $27 \mathrm{mg} / \mathrm{kg}(90$ times the human das inger mose) incroased both irsorplions an mathrions. yn sodium (338 immes the human dose) to isoprolerenol (90 times tine human dose) appears to have increased the incidence of both resorptions and maliormations.

Nursing Mothers: If is not known whether this drug is excreted in human milk Because mary druas are ex creted in human milk coution shouid be exercised when NASALCROM is od ministered to a nursing woman ministered to a nursing Pedialitic Use. Salety and effectiveness in children below the oge of years have not been established. ADVERSE REACTIONS: The most frequent adverse reactions occurring in the 430 patients included in the cin coll trials with NASALCROM were sneezing ( 1 in 10 patients), naso stinging (1 in 20) nasal burning in 25) and nosal irritation (1 in 40 ) Headoches and bod toste were pocted in ported in about 1 in 50 polients. Ep. staxis, posinasal drip, and rosh were reporied in less inan one percent ca the patients. One patient in the clinical trials developed anaphylaxis.

Adverse reoctions which have $o$ curred in the use of other cromolyn sodium formulations for inhalation in clude angioedema, joint pain and swelling urticario cough and whee ing Other reactions reported rorty

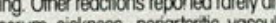
serum sickness, peniarteritic vasculins, polymyositis, pericarditis, photidermatilis, extoliative dermatitis, peripheral neuritis, and nephrosis. NASALCROM" is a registered

\section{"I LIKE HOW FAST IT WORKS TO STOP MY ALLERGIES, WITHOUT MAKING ME DROWSY."}

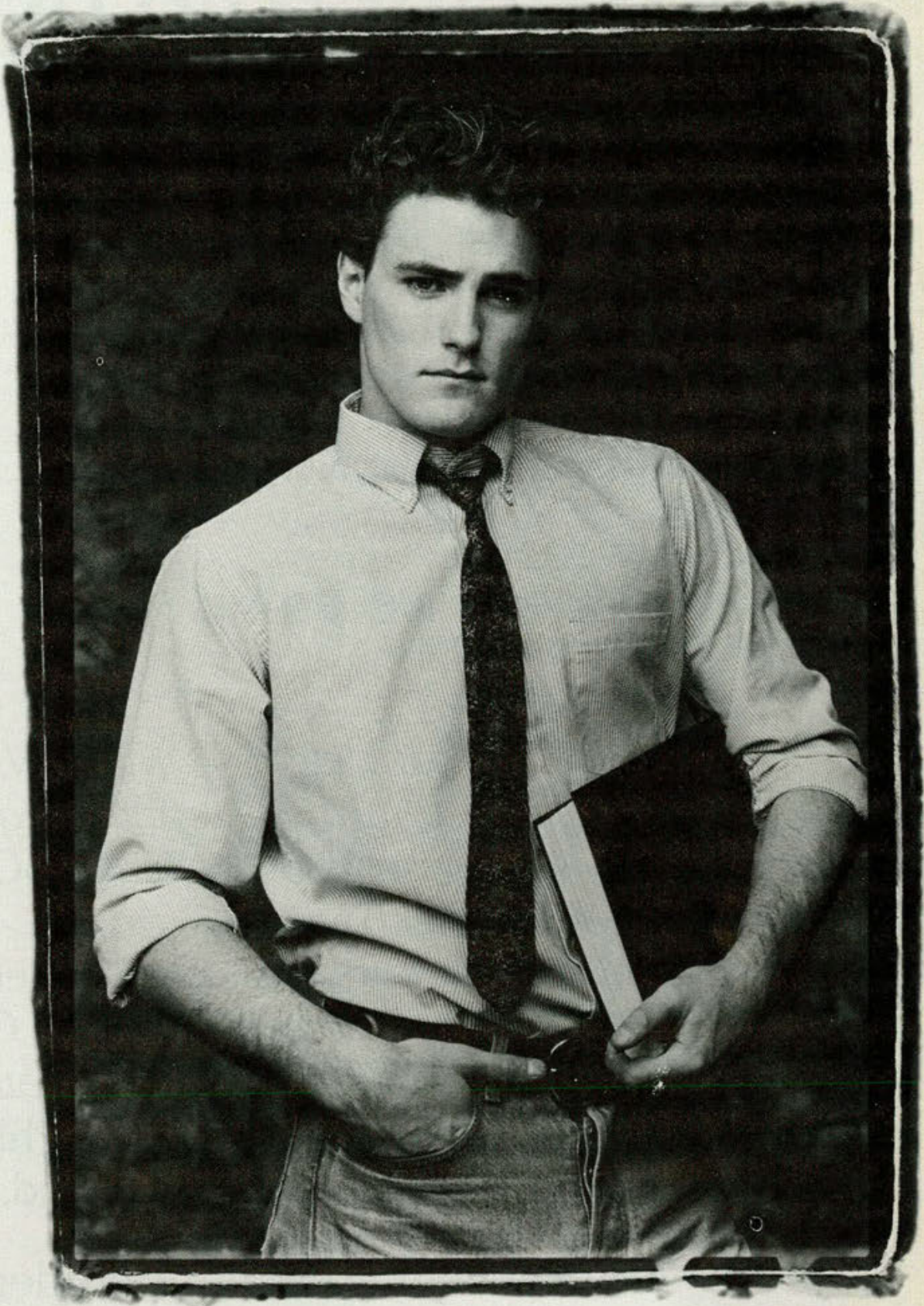

NASALCROM works rapidly-usually within the first few doses-to relieve the congestion, rhinorrhea, and sneezing of seasonal allergic rhinitis. However, for many patients, the side effects of traditional medications can be as troublesome as the allergic symptoms themselves. Unlike these medications, NASALCROM is extremely well-tolerated therapy, virtually uncomplicated by serious side effects, tolerance or contraindications.

\section{NASALCROM (cromolyn sodium/FISONS)}

Stops allergic rhinitis rapidly, without traditional side effects 


\section{OSTEOPATHIC RESEARCH: GROWTH AND DEVELOPMENT \\ - Where have we been? \\ - Where are we now? \\ - Where are we going?

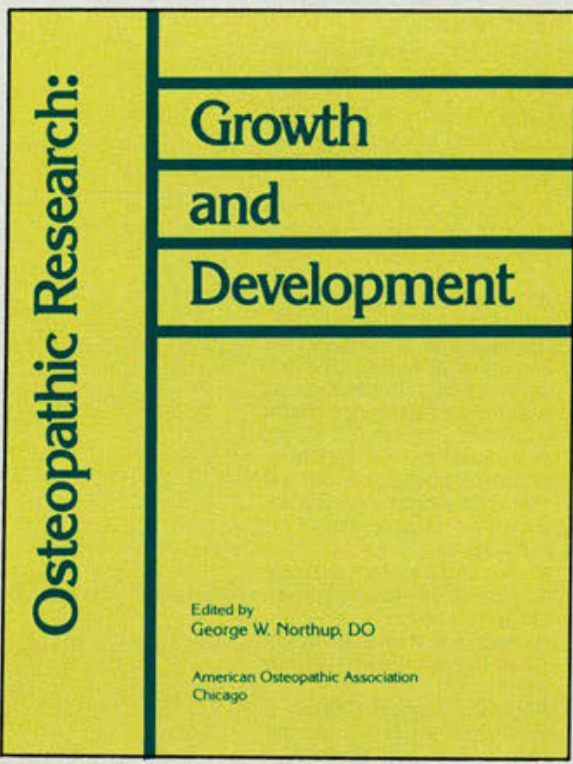

- General History-Wilbur V. Cole, DO

- Anatomical and Histopathological Evidence -Wilbur V. Cole, DO

- Biomechanics-Myron C. Beal, DO

- Physiology -Albert F. Kelso, PhD

- Clinical Research-Myron C. Beal, DO

- Status and Future of Osteopathic Research

-Albert F. Kelso, $\mathrm{PhD}$

Alexandra A. Townsend, DO

An excellent source for students, teachers, researchers, and practitioners.

Send check and order form to:

American Osteopathic Association

212 E Ohio Street

Chicago, Illinois 60611

Attn: Order Department

Please send me:

hardcover copies of Osteopathic Research: Growth and Development (\$11 each)

softcover copies of Osteopathic Research: Growth and Development (\$9 each) 


\section{For seasonal allergic rhinitis}
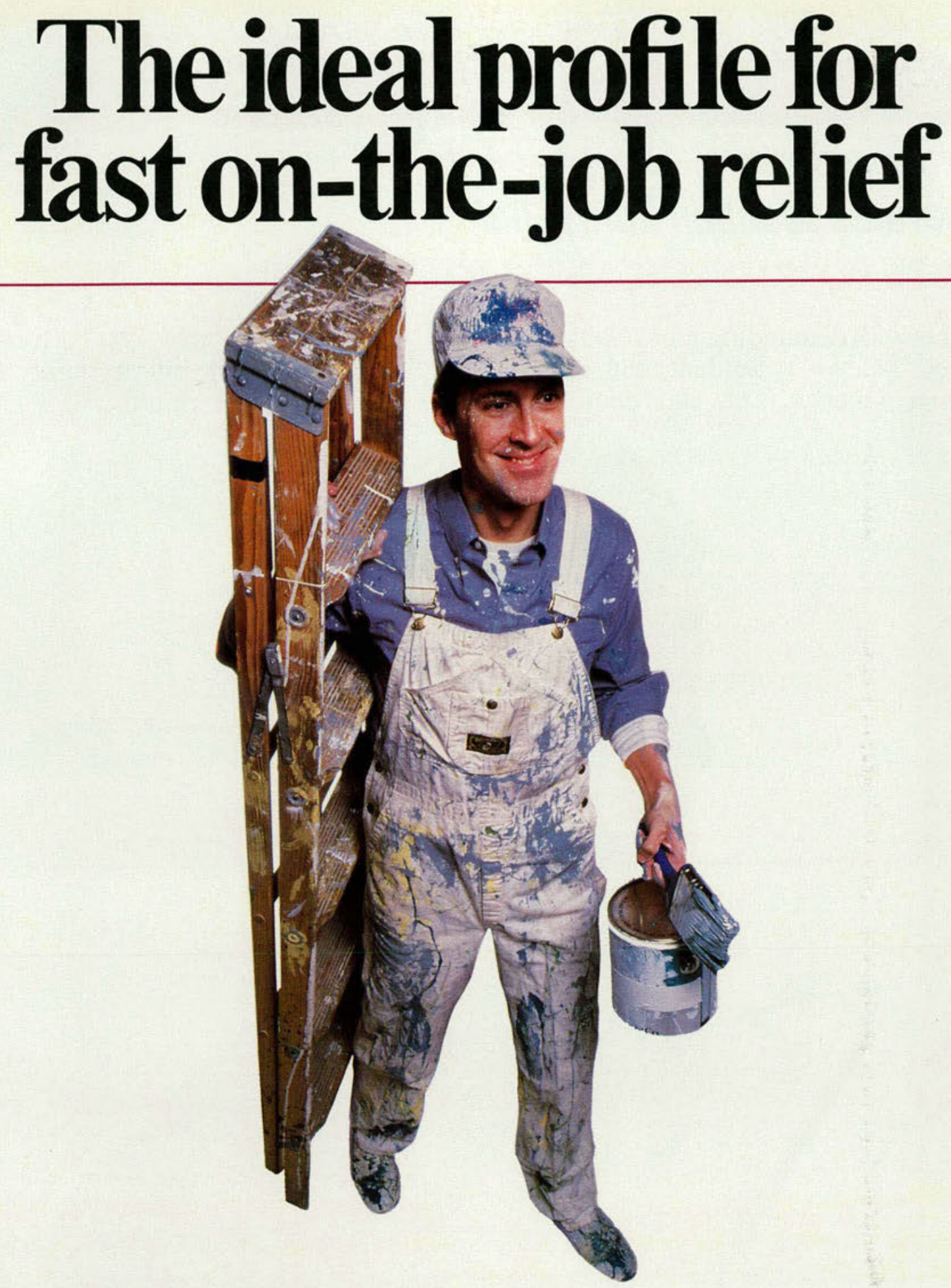

Pharmacologically distinct

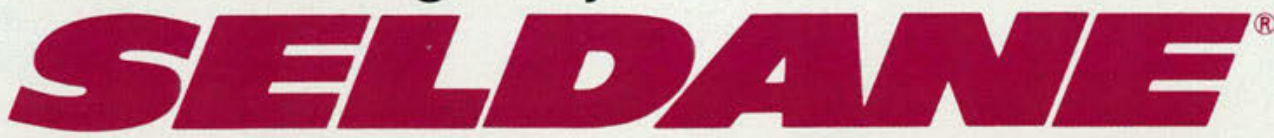

(terfenadine) $60 \mathrm{mg}$ tablets BID The \#1 prescribed allergy product in the U.S.

*Based on monthly prescription audits of single-entity antihistamines, combination antihistamine/decongestants, nasal steroids, and nasal cromolyn sodium. 
Pharmacologically distinct

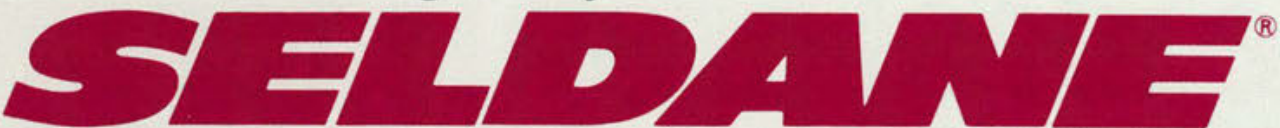

(terfenadine) $60 \mathrm{mg}$ tablets BID

Separates sedation from relief

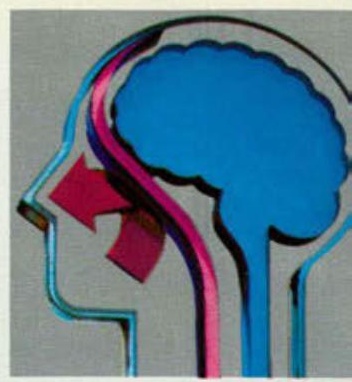

Patients with demanding jobs or busy schedules - at work or at home-can't afford to be sedated. That's why Seldane, with its distinctive therapeutic profile plus its highly desirab pharmacokinetics, is the ideal choice for treating seasonal allergic rhinitis. 


\section{For seasonal allergic rhinitis}

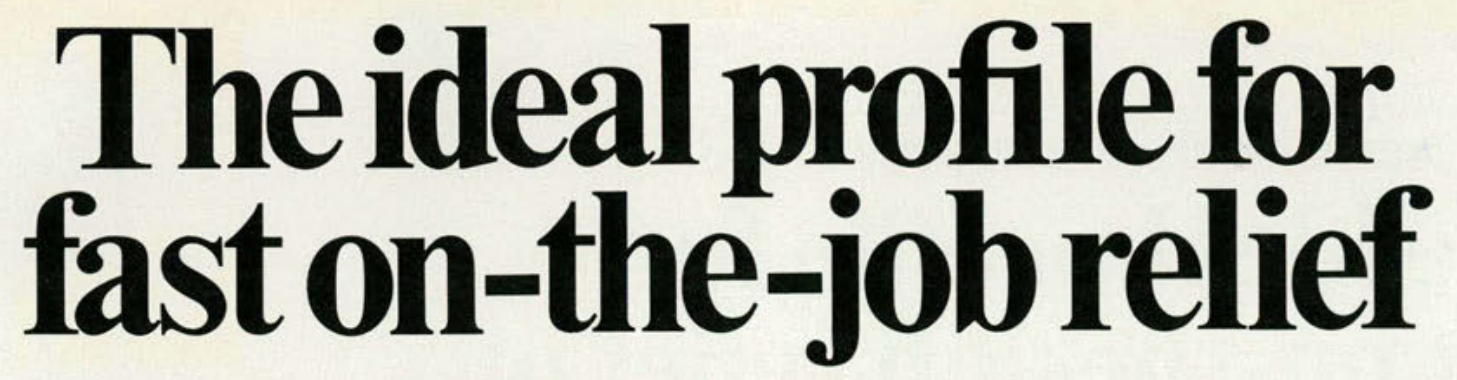

\section{nsurpassed antihistaminic potency}

Clinical studies around the world have proven Seldane ${ }^{\circledR}$ (terfenadine) as effective as assical antihistamines in relieving seasonal allergic rhinitis symptoms.

\section{eparates sedation from relief ${ }^{* *}$}

Seldane was equivalent to placebo in sedation measured by multiple sleep latency tests, ${ }^{2}$ d did not differ significantly from placebo in reported incidence of sedation in doubleind studies involving more than 1,700 patients.'

\section{ow incidence of undesired effects}

Seldane was similar to placebo in the incidence of reported adverse effects in controlled adies.

\section{apid onset of action}

Relief of symptoms within 1 hour after the first dose of Seldane was reported by most tients with hay fever. (Mean onset of action was 72 minutes.) ${ }^{3}$

\section{-hour duration of action}

Antihistaminic action for 12 hours is provided by a $60 \mathrm{mg}$ tablet of Seldane, for convenient i.d. dosing outside working hours. ${ }^{1.4 .5}$

\section{hort elimination time}

Within 24 to 48 hours after the last dose, the concentration of Seldane in the body falls low pharmacological response levels.' Repeat skin testing can be conducted without undue aiting.

\section{Inrestricted administration time}

Seldane can be taken at any time of day convenient for the patient, twice daily.

\section{xtensive worldwide experience}

Seldane is now used in 33 countries and has amassed more than 23 million patient-months experience worldwide. 


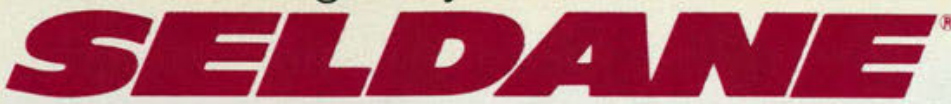

(terfenadine) $60 \mathrm{mg}$ tablets BID The \#1 prescribed allergy product in the U.S.

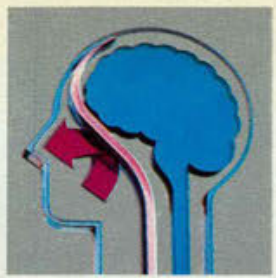

\section{The ideal profile for fast on-the-job relief of seasonal allergic rhinitis}

\section{Seldane ${ }^{\circledR}$ (terfenadine)}

$60 \mathrm{mg}$ Tablets

CAUTION: Federal law prohibits dispensing without prescription.

DESCRIPTION

Seldane (tertenadine) is available as tablets for oral administration. Each tablet contains $60 \mathrm{mg}$ terfenadine. Tablets also contain, as inactive ingredients: corn starch, gelatin, lactose. magnesium stearate, and sodium bicarbonate. Terfenadine is a histamine $\mathrm{H}_{1}$-receptor antagonist with the chemical name $\alpha$-[4-(1,1-Dimethylethyl) phenyl]-4-(hydroxydiphenyimethyl)- 1-piperidinebutanol.

It has the following chemical structure:

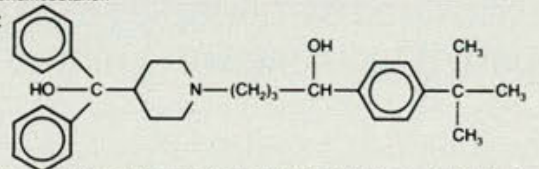

Terfenadine occurs as a white to off-white crystalline powder. It is treely soluble in chloroform, soluble in ethanol, and very slightly soluble in water.

\section{CLINICAL PHARMACOLOGY}

Terfenadine is chemically and pharmacologically distinct from other antihistamines.

Histamine skin wheal studies have shown that Seldane in single and repeated doses of $60 \mathrm{mg}$ in 64 subjects has an antihistaminic effect beginning at 1-2 hours, reaching its maximum at 3-4 hours, and lasting in excess of 12 hours. Clinical trials of Seldane involved about 2.600 patients, most receiving either Seldane, another antihistamine and/or placebo in double-blind. randomized controlled comparisons. The four best controlled and largest trials each lasted 7 days ano involved about 1,000 total patients in comparisons of Seldane $(60 \mathrm{mg}$ b.i.d.) with an active drug (chlorpheniramine, $4 \mathrm{mg}$ t.1. . . dexchlorpheniramine, $2 \mathrm{mg}$ t.i.d.: or clemastine $1 \mathrm{mg}$ b.i.d.). In the four trials, about $30-50 \%$ of placebo recipients with a significant differen moderate to complete relief of symptoms, compared with Seldane was associated with. Wiss a significant difference lavoring the active drugs in each study. In these studies. with Seldane was similar to the frequency with placebo. None of these studies showed a difterence between Seldane and other antihistamines in the frequency of anticholinergic effects. In studies which included 52 subiects in whom EEG assessments were made, no depressant effects have been observed.

Animal studies have demonstrated that terfenadine is a peripheral specific histamine $\mathrm{H}_{1}$-receptor antagonist. In these animal studies, no sedative or anticholinergic effects were observed at effective antihistaminic doses. $\mathrm{H}_{1}$-receptors indicate that, at effective antihistamine doses, neither tertenadine nor its metabolites penetrate the blood brain barrier well.

Pharmacokinetic studies in 27 male subjects. using 14C-labeled tertenadine, demonstrated that an oral dose of tertenadine is well absorbed from the gastrointestinal tract and rapidly and extensively biotranstormed. Followin administration of a single $60 \mathrm{mg}$ Seldane tablet, detectable plasma levels were observed within one-half hour. elimination half-life of 20.25 hours. Tertenadine is extensively $(97 \%)$ bound to human serum protein. Elimination studies in 6 male volunteers showed that fecal excretion accounted for $60 \%$ of the dose while $40 \%$ of the dose was eliminated via the urine. Almost all of the dose was eliminated in the form of metabolic products.

Following administration of single doses of 60 or $180 \mathrm{mg}$ of Seldane, a linear response was observed in maximum plasma concentration. Area under the curve (AUC) calculations, however, indicate a nearly four-fold increase in response for a three-fold increase in dose.

\section{INDICATIONS AND USAGE}

Seldane is indicated for the relief of symptoms associated with seasonal allergic rhinitis such as sneezing. minorrhea, pruritus, and lacrimation.

\section{CONTRAIMDICATIONS}

Seldane is contraindicated in patients with a known hypersensitivity to terfenadine or any of its ingredients.

PRECAUTIONS

Information for patients

Patients taking Seldane should receive the following information and instructions. Anthistamines are prescribed to reduce allergic symptoms. Patients should be questioned about pregnancy or lactation before starting Seldane risk to fetus or baby. Patients should be instructed to take Seldane on if as peetentiar benefit justifies the potentia dose. Patients should also be instructed to store this medication in a tightly closed container in a cool, dry place. away from heat or direct sunlight, and away from children.

Carcinogenesis, mutagenesis, impairment of fertility

Oral doses of tertenadine. corresponding to 63 times the recommended human daily dose, in mice for 18 months or in rats for 24 months, revealed no evidence of tum refig Reproduction and fertility studies in rats showed no effects on male or female fertility at oral doses of up to 21 times
the human daily dose. At 63 times the human daily dose there was a small but significant reduction in implants and the human daily dose. At 63 times the human daily dose there was a small but significant reduction in implants an were judged to be secondary to maternal toxicity.

Pregnancy Category $\mathrm{C}$

There was no evidence of animal teratogenicity. Reproduction studies have been performed in rats at doses 63 times and 125 times the human daily dose and have revealed decreased pup weight gain and survival when studies in presnant womene. Seldane should be used during pregnancy only if the potential benefit iustifies the potential risk to the fetus.

Nonteratogenic effects

Seldane is not recommended for nursing women. The drug has caused decreased pup weight gain and survival in rats given doses 63 times and 125 times the human daily dose throughout pregnancy and lactation. Effects of exposed to Seldane only during lactation are not known, and there are no adequate and well-controlled stuct

Pediatric use

Safety and effectiveness of Seldane in children below the age of 12 years have not been establishe

General

including asthma.

\section{ADVERSE REACTIONS}

Experience from clinical studies, including both controlled and uncontrolled studies involving more than patients who received Seldane, provides information on adverse experience incidence for periods of a few da to six months. The usual dose in these studies was $60 \mathrm{mg}$ twice
was as low as $20 \mathrm{mg}$ twice a day, or as high as $600 \mathrm{mg}$ daily.

In controlled clinical studies using the recommended dose of $60 \mathrm{mg}$ b. id. the incidence of reported a effects in patients receving Seldane was similar to that reported in patients receiving placebo. (See Table be ADVERSE EVENTS REPORTED IN CLINICAL TRIALS

\begin{tabular}{|c|c|c|c|c|c|}
\hline \multirow[b]{2}{*}{$\begin{array}{l}\text { Adverse } \\
\text { Event }\end{array}$} & \multicolumn{5}{|c|}{ Percent of Patients Reporting } \\
\hline & $\begin{array}{r}\text { Co } \\
\text { Seldane } \\
N=781\end{array}$ & $\begin{array}{l}\text { Introlled } \\
\text { Placebo } \\
\mathrm{N}=665\end{array}$ & $\begin{array}{l}\text { Studies" } \\
\text { Control } \\
M=626^{*}\end{array}$ & $\begin{array}{l}\text { All Clinic } \\
\text { Seldane } \\
\boldsymbol{N}=2462\end{array}$ & $\begin{array}{r}\text { Studies } \\
\text { Place } \\
\mathbf{N}=14\end{array}$ \\
\hline $\begin{array}{l}\text { Central Nervous Systern } \\
\text { Drowsiness } \\
\text { Headache } \\
\text { Fatigue } \\
\text { Diziness } \\
\text { Nervousness } \\
\text { Weakness } \\
\text { Appetite Increase }\end{array}$ & $\begin{array}{l}9.0 \\
6.3 \\
2.9 \\
1.4 \\
0.9 \\
0.9 \\
0.6\end{array}$ & $\begin{array}{l}8.1 \\
7.4 \\
0.9 \\
1.1 \\
0.2 \\
0.6 \\
0.0\end{array}$ & $\begin{array}{r}18.1 \\
3.8 \\
5.8 \\
1.0 \\
0.6 \\
0.2 \\
0.0\end{array}$ & $\begin{array}{r}8.5 \\
15.8 \\
4.5 \\
1.5 \\
1.7 \\
0.6 \\
0.5\end{array}$ & $\begin{array}{r}8 \\
11 \\
3 \\
1\end{array}$ \\
\hline $\begin{array}{l}\text { Gastrointestinal System } \\
\text { Gastrointestinal Distress (Abdominal distress, } \\
\text { Nausea, Vomiting, Change in Bowel habits) }\end{array}$ & 4.6 & 3.0 & 2.7 & 7.6 & \\
\hline $\begin{array}{l}\text { Eye, Ear, Nose, and Throat } \\
\text { Dry Mouth/Nose/Throat } \\
\text { Cough } \\
\text { Sore Throat } \\
\text { Epistaxis }\end{array}$ & $\begin{array}{l}2.0 \\
2.3 \\
0.9 \\
0.5 \\
0.0\end{array}$ & $\begin{array}{l}1.8 \\
0.2 \\
0.3 \\
0.8\end{array}$ & $\begin{array}{l}3.5 \\
0.5 \\
0.5 \\
0.2\end{array}$ & $\begin{array}{l}4.8 \\
2.5 \\
3.2 \\
0.7\end{array}$ & \\
\hline $\begin{array}{l}\text { Skin } \\
\text { Eruption (including rash and urticaria) or itching }\end{array}$ & 10 & 17 & 14 & 16 & \\
\hline
\end{tabular}

"Duration of treatment in "CONTROLLED STUDIES" was usually 7-14 DAYS

-Duration of treatment in "ALL CLINICAL STUDIES" was up to 6 months.

"CONTROL DRUGS: Chlorpheniramine (291 patients), d-Chlorpheniramine (189 patients). Clemastin

In addition to the more frequent side effects reported in clinical trials (See Table), adverse effects have reported at a lower incidence in clinical trials and/or spontaneously during marketing of Seldane that warrant as possibly associated with drug administration. These include: alopecia, anaphylaxis, angioedema, arrthy bronchospasm, confusion, depression, galactorrthea, insomnia, menstrual disorders (including dysmenor musculoskeletal symptoms, nightmares, palpitation, paresthesia, sweating, tachycardia, tremor, urinary clevations were seen in patients receiving Seld seve Mild elevations wor, or se case, moderate transam Marketing experiences include isolated reports of jaundice cholestatic hepatitis, and hepatitis: in most available intormation is incomplete. In neither the clinical trials nor marketing experience is a causal relation liver abnormalities to Seidane use clear.

OVERDOSAGE

Several cases of overdosage have been reported. Generally. signs and symptoms were absent or mild headache, nausea, confusion). However, a severe ventricular arrthythmia (torsade de pointes) developed 15 after ingestion of 56 tablets $(3360 \mathrm{mg})$ of Seldane, 14 capsules $(7000 \mathrm{mg}$ ) of cephalexin, and 2 tablets (1200

Therefore, in cases of overdosage, cardiac monitoring for at least 24 hours is recommended, along with st measures to remove any unabsorbed drug. It is not known if Seldane is dialyzable.

Treatment of the signs and symptoms of overdosage should be symptomatic and supportive after the acute Oral LDso values for terfenadine were greater than $5000 \mathrm{mg} / \mathrm{kg}$ in mature mice and rats. The oral LD 50 wa $\mathrm{mg} / \mathrm{kg}$ in newborn rats. Single doses as high as ten times $(600 \mathrm{mg})$ the recommended therapeutic dose in have been well tolerated.

DOSAGE AND ADMINISTRATION

The usual dosage for adults and children 12 years and older is $60 \mathrm{mg}$ (1 tablet) twice daily.

HOW SUPPLIED

$60 \mathrm{mg}$ tablets in bottles of 100 . Tablets are round, white, and debossed "SELDANE". Store table $\left(40^{\circ} \mathrm{C}\right)$ and moisture.

Product Information as of January, 1987

MERRELL DOW PHARMACEUTICALS INC.

Subsidiary of The Dow Chemical Company

Merrell Dow

References:

1. Data available upon request, MERRELL DOW PHARMACEUTICALS INC., Cincinnati, Ohio 45215. 2. Roehrs TA, Tietz EI. Zorick FJ, et al: Daytime sleepiness and antihistamines. Sleep 7 (2):137-141, 1984.3. Murphy-O'Connor JC, Renton RL. Westiake DM: A double-blind comparative trial of two dose regimens of terfenadine in patients with hay fever. J Int Med Res 12:333-337, 198 4. Hüther KJ, Renftle G, Barraud N, et al: Inhibitory activity of terfenadine in histamine-induced skin wheals in man. Eur J Clin Pharmacol 12:195-199, 1977. 5. Reinberg A, Levi F, Guillet P, et al: Chronopharmacological study of antihistamines in man with special references to terfenadine. Eur J Clin Pharmacol 14:245-252, 1978.

7-0119U (SE034A) MDA 017R JANUARY, 1987 